\title{
Dominance hierarchies in xanthid crabs: roles in resource-holding potential and field distributions
}

\author{
Kenneth M. Brown ${ }^{1, *}$, Sean F. Keenan ${ }^{2}$, Patrick D. Banks ${ }^{3}$ \\ ${ }^{1}$ Department of Biological Sciences, and ${ }^{2}$ Department of Oceanography \& Coastal Sciences, Louisiana State University, \\ Baton Rouge, Louisiana 70803, USA \\ ${ }^{3}$ Marine Fisheries Division, Louisiana Department of Wildlife and Fisheries, Baton Rouge, Louisiana 70808, USA
}

\begin{abstract}
We used laboratory experiments to determine the dominance hierarchy of 3 xanthid crabs occurring along the Louisiana Gulf of Mexico coast. Juveniles of the stone crab Menippe adina were dominant over adult Eurypanopeus depressus, which were in turn dominant over adult Panopeus simpsoni. The relationship of agonism to body size differed among species, with larger stone crabs initiating fewer behaviors of all types, while agonism was more frequent in medium-sized P. simpsoni and large E. depressus. Even when stone crabs were smaller than the other 2 species, they exibited similar levels of agonism, perhaps explaining how juvenile stone crabs can coexist with and grow through the size range of the 2 small xanthids before the emigrate from oyster reefs to pursue a solitary existence as adults. As predicted by game theory, for both food and shelter resources, dominance hierarchy predicted resource-holding potential (RHP). Stone crabs were more successful at acquiring and defending resources than $P$. simpsoni, and RHP for shelter was not reversed when stone crabs were smaller. A year-long field sampling study indicated that both $M$. adina and $E$. depressus were more common in subtidal habitats with shelter, while $P$. simpsoni was more abundant in an intertidal oyster reef and on a mud flat lacking shelter. We argue that these distributions could be explained by the lower ranking of $P$. simpsoni in the dominance hierarchy, and that behavioral interactions may thus play a role in shaping mud crab distributions, and deserve study of their role in explaining the distribution of other crabs as well.
\end{abstract}

KEY WORDS: Agonism $\cdot$ Dominance hierarchy $\cdot$ Mud crabs $\cdot$ Distributions

\section{INTRODUCTION}

Game theory models provide a mechanism to predict when agonistic behavior will evolve, based on relative benefits and costs to individuals (Maynard Smith 1982, Huntingford \& Turner 1987). The models predict that agonism should become more intense as the contested resource becomes more valuable, and that body size should be a good predictor of the ability to secure resources (resource-holding potential or RHP, Austad 1989). These models have successfully predicted patterns of interactions in organisms as varied as jumping spiders (Austad 1989), portunid crabs (Smith et al. 1994) and African cichlids (Turner \& Huntingford 1986).

In marine crustaceans, shelter and food resources are often vigorously defended (Dingle 1983), and pre- dation risk may be responsible for the evolution of interspecific aggressive behavior to defend refugia (Steger 1987). Interference competition through aggressive interactions has been implicated in resource partitioning in stomatopods (Steger 1987), as well as both predatory intertidal crabs (Navarette \& Castilla 1990) and herbivorous coral-inhabiting crabs (Huber \& Coles 1986). Body size is a good predictor of RHP in crabs, although the relative size of chelae may be a more accurate predictor (Sneddon et al. 1997a). Also as predicted by theory, similar-sized crabs do fight more intensively, with resulting costs such as elevated respiration rates (Huntingford et al. 1995). Aggressive interactions among crabs also result in other costs, such as reduced feeding rates and emigration of subordinate individuals (Mansour \& Lipscius 
1991, Iribarne et al. 1994, Sneddon et al. 1997b, Clark et al. 1999).

In this paper, we investigate the role of agonism in the ecology of 3 xanthid crabs common along the northern Gulf of Mexico. First we determined the dominance hierarchy of all 3 species using pair-wise interactions in a laboratory experiment. In this same experiment, we also explored the role of body size in explaining both the frequency of agonistic and subserviant behaviors in each species. Also based on this initial experiment, we used the a priori determination of relative dominance to pair the most and the least dominant species in experiments with added resources (either shelter or food) to determine whether dominance predicts RHP. The most and least dominant species were chosen to most clearly illustrate the role of dominance in determining RHP. Finally, we sampled 3 field sites differing in tidal height and shelter availability to see if the dominance hierarchy was a good predictor of field distributions.

Xanthid or mud crabs are ubiquitous inhabitants of oyster reefs along the SE Atlantic and Gulf coastlines of the United States, reaching densities as high as $50 \mathrm{~m}^{-2}$ (McDonald 1982, Guillory et al. 2001). In northern Gulf of Mexico oyster reefs, 3 species of xanthid crabs are common: Mennipe adina (Williams et Felder), Panopeus simpsoni (= P. herbstii $(\mathrm{H}$. Milne Edwards)), and Eurypanopeus depressus (Smith). The latter 2 species spend their whole life cycle as commensal organisms on oyster reefs, but stone crabs emigrate from reefs when they are about $4 \mathrm{~cm}$ in carapace width $(\mathrm{CW})$, and are then solitary, defending cavities or burrows as adults and reaching a $\mathrm{CW}$ as large as $12 \mathrm{~cm}$ (Guillory et al. 2001). In contrast, adult P. simpsoni reach a size of $5 \mathrm{~cm}$, and $E$. depressus only $2 \mathrm{~cm}$ CW (McDonald 1982). Mud crab species often occur in pairs, and differences in vertical distribution, feeding niches or salinity tolerances may limit competition (May 1974, Menendez 1987, Lee \& Kneib 1994, Meyer 1994). Smaller species may be able to more effectively use crevices between oysters as refugia from predators. More is known about the ecology of adult stone crabs than other, smaller xanthids because of their economic importance. Lindberg et al. (1990) found that adult stone crabs preferred widely-spaced artificial shelters, which they interpreted as being due to lower rates of resource depletion. Beck $(1995,1997)$ argued that suitable refugia were limited for stone crab adults, causing a bottleneck for crab population dynamics. However, since stone crabs must again co-exist with other, smaller mud crabs and grow through their size range, it is also possible that survival of juveniles may create a bottleneck, similar to the case of freshwater sunfish, where juveniles of different species are forced to co-occur in vegetation to escape predators, even though the adults have quite different ecologies (Mittelbach 1988). Indeed, Shervette et al. (2001) found that smaller refugia had higher occupancy rates by mud crabs, although occupancy was always below $30 \%$, leading these authors to conclude that refugia were not limiting. However, occupancy rates did decline in the presence of stone crabs, arguing for a possible role of agonism. Lindberg's et al. (1990) observation of an overdispersion of adult stone crabs could also be explained by agonism. We therefore consider that the role of aggression among mud crab species needs to be studied more fully.

\section{MATERIALS AND METHODS}

Sampling. Crabs were collected near the Louisiana Universities Marine Consortium laboratory near Port Fourchon, Louisiana, about $140 \mathrm{~km}$ south of New Orleans, USA. An intertidal oyster reef behind the laboratory, a nearby subtidal oyster reef, and a subtidal mudflat adjacent to the intertidal oyster reef were sampled for a year-long period from September 1998 to August 1999. The laboratory is located along a bayou tributary of the larger Bayou La Fourche, about $10 \mathrm{~km}$ inland from the Gulf of Mexico. The area is protected from waves and salinities average about 25 PSU. A more detailed description of the sites and the surrounding areas can be found in Brown (1997).

We filled 3 mesh bags $(0.67 \times 0.33 \mathrm{~m}$, mesh size $=$ $1.6 \mathrm{~cm}$ ) with oyster shell (Stuck \& Perry 1992) and set them out monthly for month-long periods at each site. Bags were carefully retrieved and placed in tubs to avoid loss of smaller crabs. The shell was washed over a series of sieves, crabs identified, and carapace widths (including anterior-lateral spines) measured to the nearest $0.1 \mathrm{~mm}$ with dial calipers. Oyster reefs are difficult habitats to quantitatively sample because of the aggregated growth pattern and sharp shell margins of the oysters, and the shell bags provide an easily replicated, quantifiable estimate of the abundance of mud crabs (Stuck \& Perry 1992). The smallest crabs collected in the bags were about $5 \mathrm{~mm} \mathrm{CW}$, and so the bags probably measured both recent recruitment into the population as well as immigration of crabs from surrounding habitats. Crab abundances per bag were subjected to a factorial analysis of variance. Because stone crabs were absent from 1 of the 3 habitats (see 'Results'), the design was a 3-way factorial (all 3 species $\times$ the 2 remaining habitats $\times 12$ mo). Analyses were performed using SAS techniques (SAS Institute 1988), and Tukey's a posteriori tests were used to test for significant differences among means.

Dominance experiments. Crabs were systematically paired so that all species pairings were replicated, with 
trials including individuals of equal size, and with each species larger ( $\mathrm{N}=5$ to 10 pairs per species and relative size combination). Size pairings $(S)$ were based on an index developed by Sinclair (1977):

$$
S=\left(|\triangle \mathrm{CW}| / \mathrm{CW}_{\mathrm{L}}\right)+\left(|\Delta \mathrm{PL}| / \mathrm{PL}_{\mathrm{L}}\right)
$$

where $|\mathrm{CW}|$ and $|\mathrm{PL}|$ are the absolute values of differences in carapace width and propodus length, and $\mathrm{CW}_{\mathrm{L}}$ and $\mathrm{PL}_{\mathrm{L}}$ are the respective dimensions for the larger crab. If $S>0.2$, the crabs were considered to be unequal in size. Crabs were held in 21 of aerated seawater (25 PSU, 14:10 h light:dark) with oyster shell provided as shelter. Crabs were used within $2 \mathrm{~d}$ for experiments, and were not kept in the laboratory for more than 2 wk.

Crabs were then paired in $10.5 \mathrm{~cm}$ glass dishes, with a semi-permeable partition to prevent interaction. After $5 \mathrm{~min}$, the partition was removed and interactions were videotaped for $2 \mathrm{~h}$ using time-lapse VCR, because preliminary trials had indicated the frequency of interactions declined after $1.5 \mathrm{~h}$. We grouped behaviors into 3 categories (Table 1) and noted which individual initiated which behavior. Advances, grasps, envelopments and fights were all considered agonistic behaviors, retreats were considered submissive, and meral spreads were considered as threat displays not necessarily indicating intent (i.e. 'bluffing') (Sinclair 1977, Dingle 1983).

For each species pair and behavioral category, we tested the null hypothesis that the distribution of behaviors between species was independent of relative size with a G-test of independence (Sokal \& Rohlf $1995)$ and a $2 \times 3$ contingency table ( 2 species, 3 relative size comparisons). Each comparison has 2 degrees of freedom, and $G$-values are compared to a $\chi^{2}$ distribution. We interpreted causes of significance by plotting deviations from expected values; since contrasts were binary, deviations are given for only 1 of the crab species (the deviation for the other species is equal and opposite in sign). We also give the number of behaviors scored for each contrast to illustrate sample sizes.

The behaviors scored for all 5 to 10 pairs were thus pooled for each species comparison and relative size category. Although this may have masked some variation among trials within size or species categories, the non-parametric test does not make all the assumptions of a parametric ANOVA, and since non-parametric tests are less powerful, should be more conservative in illustrating differences. As mentioned above, results can also be easily interpreted as deviations from ex- pected values. For example, if a species is more aggressive, then a large positive deviation should occur for the frequency of agonistic behaviors, as well as a large negative deviation for avoidances. Similarly, for the analysis of size-based differences in behaviors (see next paragraph), large deviations (either positive or negative) in a particular size class indicate clear size-dependency in interactions.

In this same experiment, to determine the correlation of body size with behavioral frequencies, we divided crabs into 3 size categories for Menippe adina (small = 12 to $15.9 \mathrm{~mm}$, medium $=16$ to $19.9 \mathrm{~mm}$, large $=10$ to $25 \mathrm{~mm} \mathrm{CW}$ ) and Panopeus simpsoni (small $=9$ to $14.9 \mathrm{~mm}$, medium = 15 to $19.9 \mathrm{~mm}$, large $=20$ to $27 \mathrm{~mm}$ CW) but only 2 categories for Eurypanopeus depressus $($ small $=10$ to $14.9 \mathrm{~mm}$, large $=15$ to $20 \mathrm{~mm} \mathrm{CW})$ because of its smaller size range. We predicted from game theory arguments that the frequency of agonistic acts should increase with increasing body size, while the frequency of bluffing and retreats should decrease with increasing body size. We used $G$ goodness-of-fit tests (Sokal \& Rohlf 1995) to test the relationships with size. We again assessed size-dependent trends by plotting deviations from expected values for each species.

Resource-holding potential. In these experiments, we used only Menippe adina and Panopeus simpsoni because: (1) being at opposite ends of the dominance hierarchy, we were maximizing the chances of finding dominance-related trends in RHP, (2) these species are roughly similar in size, and (3) both are carnivores, whereas Eurypanopeus depressus is an omnivore. Using crabs of roughly similar size allowed us to conduct 2 treatments: pairings with equal-sized crabs for both species (using the same body size index), and pairings with larger $P$. simpsoni (to determine if the RHP would be reversed if the normally submissive species were larger). Using the 2 species with similar foraging patterns assured that the shrimp were an appro-

Table 1. Menippe adina, Panopeus simpsoni and Eurypanopeus depressus. Ethogram of behavioral acts observed in pair-wise interactions of xanthid crabs, and their grouping into categories for statistical analysis

\begin{tabular}{ll}
$\begin{array}{l}\text { Category } \\
\text { Behavior }\end{array}$ & \multicolumn{1}{c}{ Description } \\
\hline $\begin{array}{c}\text { Agonistic } \\
\text { Advance }\end{array}$ & Approach to within 1 carapace width of opponent \\
Grasp & Strike or hold opponent with chela \\
Envelop & Embrace opponent's carapace with both chelae \\
Fight & Initiate repeated grasps and envelopments \\
$\begin{array}{c}\text { Bluff } \\
\text { Meral spread }\end{array}$ & Extend both chelae laterally when opponent advances \\
$\begin{array}{c}\text { Submissive } \\
\text { Retreat }\end{array}$ & Avoid after interaction or when opponent advances
\end{tabular}


priate contested resource; 6 pairs of crabs were paired for each species and relative-size comparison.

Male crabs, starved for $2 \mathrm{~d}$, were paired for $30 \mathrm{~min}$ and videotaped in the circular dishes, light regimens and salinities used in the earlier experiments. We provided 2 resources in separate trials, i.e. a food resource (a small piece of shrimp), or an oyster shell (roughly $7 \mathrm{~cm}^{2}$ in area) for shelter. Retreat from an interaction received a score of -1 , initiating an interaction a score of +1 , causing the opponent to retreat a score of +2 , securing a resource (either food or shelter) a score of +3 , and +4 if the other crab were displaced while securing the resource. Scores were summed for each crab over the $30 \mathrm{~min}$ trial. We tested the hypothesis that RHP (i.e. the total score for a crab) was not affected by species or relative size by a 1-way Kruskal-Wallis non-parametric analysis of variance $(H$, Conover 1999) comparing all 4 species-size categories. Critical values for the test statistic were determined from a $\chi^{2}$ distribution.

\section{RESULTS}

\section{Dominance experiments}

For Menippe adina (MA) paired with Panopeus simpsoni (PS) (Fig. 1a), agonism was not independent of relative body size $(G=27.2, \mathrm{p}<0.001)$. The large positive deviations for agonistic acts initiated by stone crabs in the first 2 comparisons (MA > PS and MA = PS) indicated they were more aggressive when they were the larger of the crab pair or when equally matched in body size, but did not deviate from expected values if they were the smaller of the pair. Avoidances were also dependent on body size (Fig. 1a, $G=51.2$, p < 0.001), with large negative deviations for avoidances by stone crabs indicating they avoided less than expected when larger or equal in size (MA > PS and MA = PS), and did not deviate from expected values when smaller. The frequency of meral spreads was independent of body size $(G=5.6, \mathrm{p}>0.05)$.

When Menippe adina and Eurypanopeus depressus (ED) were paired, stone crabs again initiated more agonistic behaviors than expected when larger or equal in size (i.e. positive deviations when MA > ED and $\mathrm{MA}=\mathrm{ED}$, Fig. 1b) and did not deviate from expectations when smaller. Agonism was thus again dependent on relative body size $(G=21.7, \mathrm{p}<0.001)$. Avoidances by stone crabs were also dependent on body size $(G=74.3$, p < 0.001$)$, with negative deviations indicating fewer than expected avoidances when stone crabs were larger, small deviations indicating similarity to expected values when similar in size, and more than expected numbers of deviations when smaller in size than E. depressus. The frequency of meral spreads was again independent of relative body size $(G=2.2, \mathrm{p}>0.05)$, and negative deviations in all 3 categories indicated that fewer
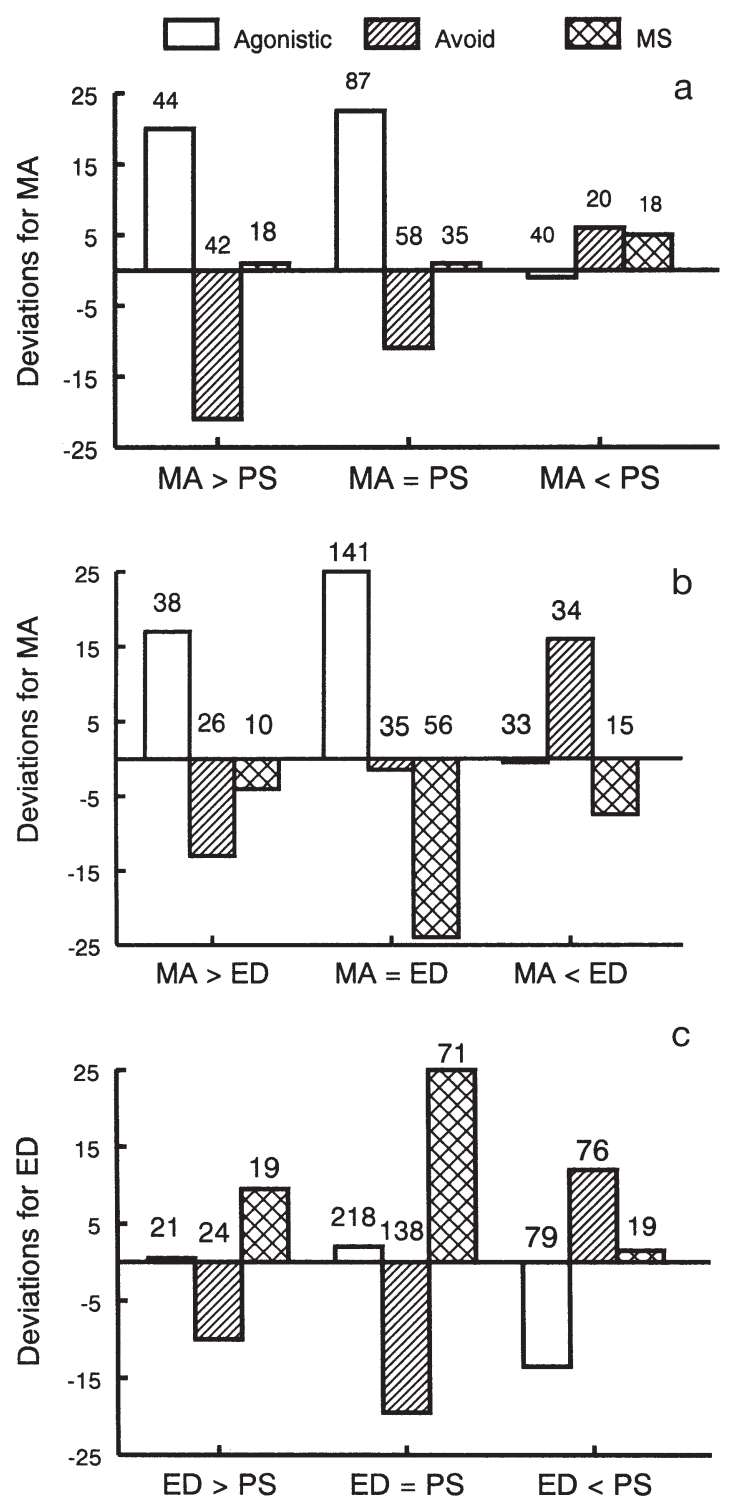

Fig. 1. Menippe adina, Panopeus simpsoni and Eurypanopeus depressus. Deviations from expected values for 3 categories of behavior initiated by paired xanthid crabs in 3 size categories. (a) M. adina (MA) paired with P. simpsoni (PS). MA > PS: MA larger than PA; MA = PS: both of equal size, $\mathrm{MA}<\mathrm{PS}$ : MA smaller than PS. (b) MA paired with E. depressus (ED). MA > ED: MA larger than ED MA = ED: both of equal size; MA < ED: MA smaller than ED. (c) ED paired PS. ED > PS. ED > PS: ED larger than PS; ED = PS; both of equal size; $E D<$ PS: ED smaller than PS. In each panel, 'Agonistic': total number of aggressive acts (see Table 1); 'Avoid': number of avoidances; MS: number of meral spreads initiated; numbers above histograms: number of behaviors scored for both species 
meral spreads were initiated by stone crabs than by E. depressus.

For Panopeus simpsoni and Eurypanopeus depressus, small deviations from expected values for the number of agonistic acts initiated by E. depressus indicated that both species were equally aggressive when of equal body size (i.e. ED = PS), or when E. depressus were larger (ED > PS, Fig. 1c). When P. simpsoni was larger, however, it initiated more aggressive behaviors (i.e. there was a large negative deviation for $E$. depressus, $G=8.0, \mathrm{p}<0.05)$. Regarding avoidances, $E$. depressus avoided less than expected when it was larger or equal in size (i.e. negative deviations for E. depressus for ED = PS and ED > PS), only avoiding more than expected when $P$. simpsoni was larger $(G=$ $33.2, \mathrm{p}<0.001)$. For meral spreads, E. depressus initiated more (i.e. positive deviations for ED = PS and ED $>$ PS) unless it was smaller than $P$. simpsoni, when frequencies were near expected values $(G=14.5$, p < 0.001).

\section{Body size and agonism}

In Menippe adina, the frequency of agonistic acts $(G=46.8, \mathrm{p}<0.01)$, avoidances $(G=117.1, \mathrm{p}<0.01)$ and meral spreads $(G=59.8, \mathrm{p}<0.01)$ decreased with increasing body size (i.e. deviations were positive in the smallest size class, but negative in the larger 2 size classes, Fig. 2a). In Panopeus simpsoni, agonistic acts were most frequent for intermediate-sized crabs (i.e. positive deviation for only the intermediate size class, Fig. 2b, $G=19.1, \mathrm{p}<0.05)$. In comparison, the small deviations indicate avoidances $(G=6.2, \mathrm{p}>$ $0.05)$, and meral spreads $(G=2.4, \mathrm{p}>0.05)$ were not related to body size. In contrast, for Eurypanopeus depressus, the frequency of agonistic acts (Fig. 2c, G $=58.2, \mathrm{p}<0.01)$ and meral spreads $(G=63.8, \mathrm{p}<$ 0.01 ) increased with increasing body size (i.e. deviations were positive in the larger size class), while the frequency of avoidances was not affected by body size $(G=1.6, \mathrm{p}>0.05)$.

\section{Resource-holding potential}

For food resources, higher average scores on the behavioral index for stone crabs indicated that Menippe adina had greater RHP when the carapace widths of both crabs were similar (MA = PS, Fig. 3), but RHP was reversed when Panopeus simpsoni was larger (MA $<\mathrm{PS}, H=17.2$, $\mathrm{p}<0.05)$. For shelter, $M$. adina again had the better RHP when equal in size to $P$. simpsoni, and equal RHP when smaller $(H=9.4$, $\mathrm{p}<0.05)$.

\section{Field distributions}

There were clear differences in abundance per bag (Table 2) among the 3 crab species, with stone crabs being completely absent from the bags in the subtidal mud flat, although the other 2 species did recruit to the subtidal mudflat bags. As stated in 'Materials and methods', a factorial ANOVA was therefore conducted on the abundances of all 3 species in the remaining

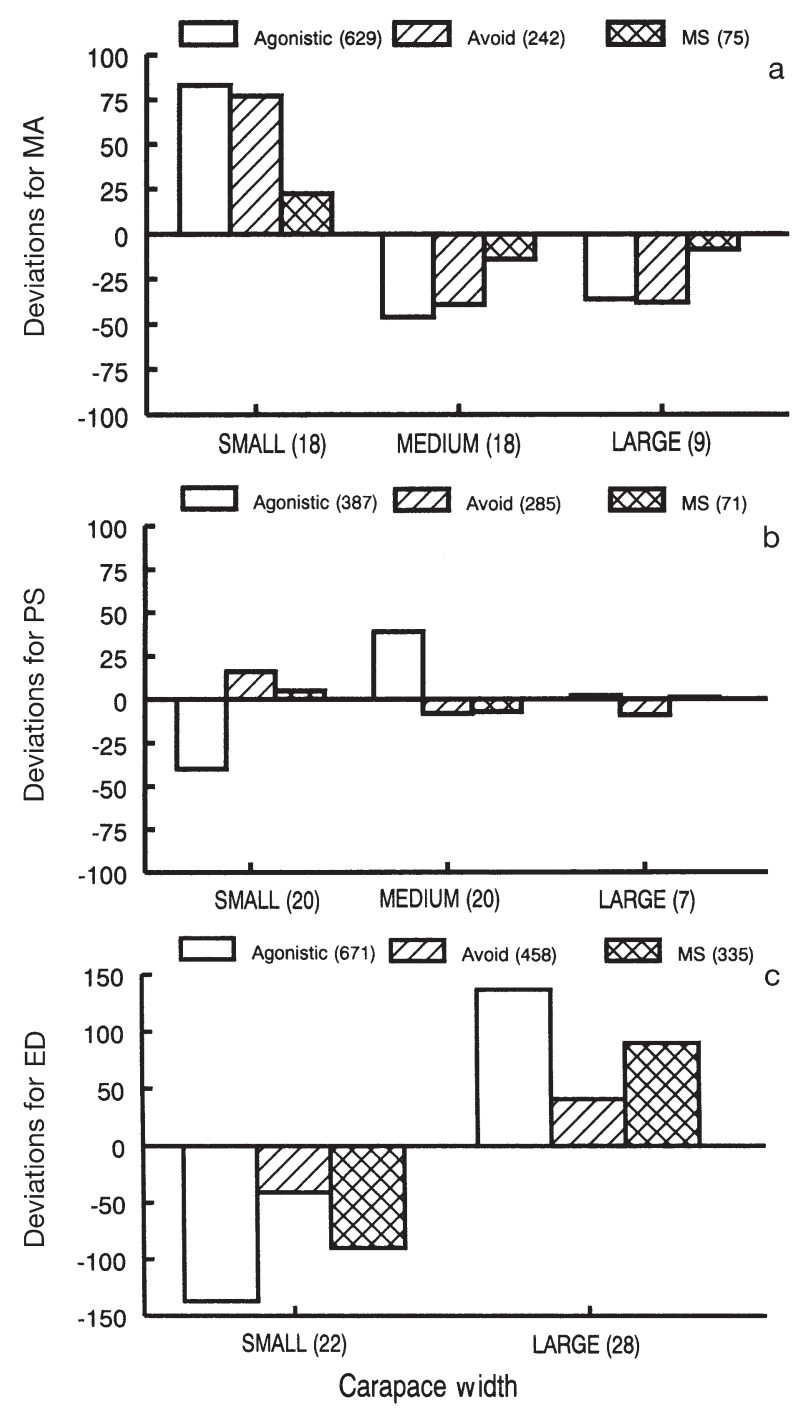

Fig. 2. Menippe adina, Panopeus simpsoni, and Eurypanopeus depressus. Deviations from expected values for 3 categories of behaviour initiated by xanthid crabs in different size categories. (a) $M$. adina, 3 size categories; (b) $P$. simpsoni, 3 size categories; (c) E. depressus, 2 size categories. In each panel, numbers in parentheses after the various behaviours show number of behaviours scored (further details as in Fig. 1 legend); sizes on $x$-axis: midpoints (size range given in 'Materials and methods'), followed by number of crabs in each size category (in parentheses) 


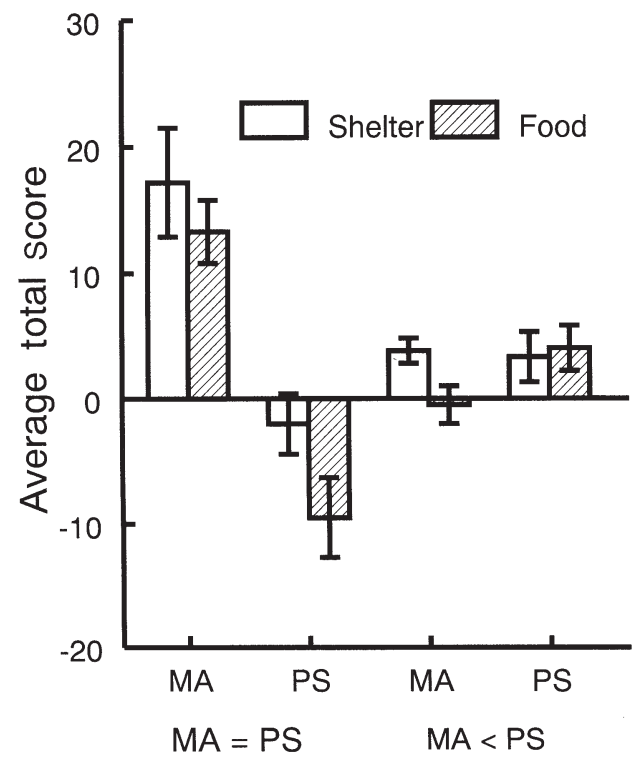

Fig. 3. Menippe adina (MA) and Panopeus simpsoni (PS). Dependency of resource-holding potential (RHP) on relative size. Values are average $( \pm \mathrm{SE}, \mathrm{N}=6$ pairs $)$ total scores of RHP index for paired crabs given 2 resources (shelter and food) when both species had equal carapace widths $(\mathrm{MA}=\mathrm{PS})$, or when $P$. simpsoni was larger $(\mathrm{MA}<\mathrm{PS})$. (See 'Materials and methods' for details of how scores were tabulated to estimate RHP)

2 habitats. There were significant differences in abundance among the 3 species $(F=451.1, \mathrm{p}<0.0001)$, the 2 habitats $(F=56, \mathrm{p}<0.001)$, and months $(F=16.4, \mathrm{p}<$ 0.001). However, the species $\times$ site, species $\times$ month, site $\times$ month and 3-way interaction were also highly significant. The a posteriori comparisons indicated that Eurypanopeus depressus (grand average of 20.4 crabs bag $^{-1}$ pooled over all months and habitats) was significantly more abundant than Panopeus simpsoni (3.2 crabs bag $\left.{ }^{-1}\right)$, which was in turn more abundant than Menippe adina $\left(0.6 \mathrm{crabs}_{\mathrm{bag}^{-1}}\right)$. Pooled over all species and months, crabs were significantly more abundant subtidally (grand average of 10.2 crabs

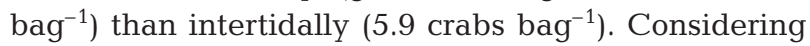

Table 2. Menippe adina, Panopeus simpsoni and Eurypanopeus depressus. Mean $( \pm \mathrm{SE})$ carapace widths (sample sizes in parentheses) and mean $( \pm \mathrm{SE})$ abundance per bag for $(\mathrm{N}=36)$ for xanthid crabs collected over year-long period from 3 habitats

\begin{tabular}{|lcccc|}
\hline \multirow{2}{*}{ Species } & $\begin{array}{c}\text { Carapace } \\
\text { width (mm) }\end{array}$ & $\begin{array}{c}\text { Intertidal } \\
\text { oyster reef }\end{array}$ & $\begin{array}{c}\text { Subundald } \\
\text { oyster reef }\end{array}$ & $\begin{array}{c}\text { Subtidal } \\
\text { mud flat }\end{array}$ \\
\hline M. adina & $14.5 \pm 0.1(27)$ & $0.03 \pm 0.03$ & $1.2 \pm 0.2$ & 0 \\
P. simpsoni & $14.7 \pm 0.5(93)$ & $4.9 \pm 0.6$ & $1.3 \pm 0.4$ & $3.7 \pm 0.1$ \\
E. depressus & $9.9 \pm 0.1(667)$ & $12.6 \pm 1.2$ & $27.8 \pm 3.3$ & $5.1 \pm 1.2$ \\
\hline
\end{tabular}
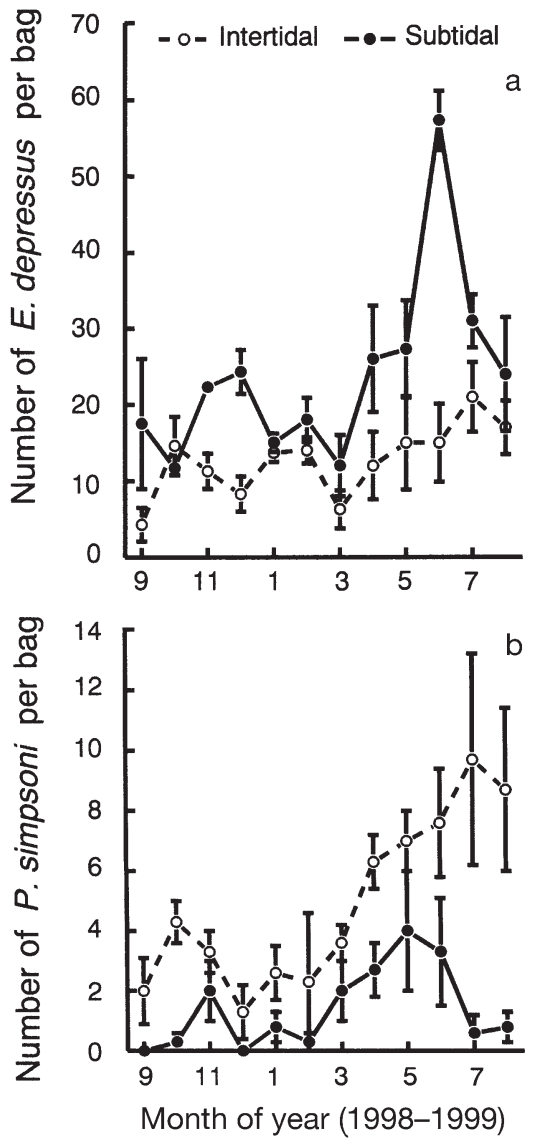

Fig. 4. (a) Eurypanopeus depressus. (b) Panopeus simpsoni. Mean $( \pm \mathrm{SE}, \mathrm{N}=3)$ abundance $\mathrm{bag}^{-1}$ in an intertidal and a subtidal oyster reef along the Gulf of Mexico coastline near Port Fourchon, Louisiana, over a 12 mo interval. For clarity, only every second month is indicated on $x$-axis. Note different scales of the $y$-axes, necessary because E. depressus was more abundant (see 'Results')

species and habitats together, E. depressus was the most abundant subtidally $\left(28 \mathrm{bag}^{-1}\right)$, followed by intertidally $\left(12.7 \mathrm{bag}^{-1}\right)$, followed by $P$. simpsoni intertidally $\left(4.9 \mathrm{bag}^{-1}\right)$, with no differences in the abundances of all other species-habitat combinations.

Plotting the abundances of Eurypanopeus depressus and Panopeus simpsoni in both habitats against time (Fig. 4) clearly revealed the differences in habitat preference and seasonal trends in abundance indicated by the significant interaction terms and $a$ posteriori tests. First, both crabs were usually most abundant in the summer months, indicating that increased abundances could be caused by recruitment of newly metamorphosed crabs, which occurs during these 
months (McDonald 1982, Stuck \& Perry 1992). Second, during most months, E. depressus was clearly more abundant in the subtidal reef (Fig. 4a), and P. simpsoni in the intertidal reef (Fig. 4b). Finally, there was a significant pulse of abundance for E. depressus late in the summer subtidally that was correlated with a significant decrease in the abundance of $P$. simpsoni subtidally, even though $P$. simpsoni was increasing in abundance intertidally, suggesting possible nichepartitioning or competition.

Since stone crabs were again not found in all 3 habitats, a complete factorial analysis of variance of size was not possible, and we therefore did a 1-way analysis of variance comparing carapace widths for all 3 species, pooled over all habitats, which indicated that Eurypanopeus depressus was smaller on average than the other 2 xanthids (Table 2, $F=1109$ ).

\section{DISCUSSION}

Our behavioral experiments suggest a dominance hierarchy among the 3 xanthids, with Menippe adina the most dominant, Eurypanopeus depressus intermediate, and Panopeus simpsoni the least aggressive. Supporting evidence comprises: (1) M. adina is always more agonistic when individuals are larger or of similar size; (2) $M$. adina is at least equally aggressive when smaller in size, although it does avoid larger $E$. depressus; (3) $P$. simpsoni initiates an equal number of agonistic acts when paired with $E$. depressus, but usually avoids the latter species. The frequency of avoidances is probably the most critical behavior, as subserviant crabs would probably leave the area under field conditions. Meral spreads do appear to veil intent (i.e. are an example of 'bluffing' behavior) since both subordinate species execute more meral spreads when interacting with $M$. adina.

The observed relationship of behavior to crab body size was more complicated than expected. Although we again expected from game theory arguments that agonistic behaviors would increase with increasing body size, and bluffing and submissive behaviors would decrease, the size-specific relationships differed among the crab species. Larger stone crabs were less behaviorally active in general, indicating that they may simply ignore subordinate individuals. For the other 2 species, agonistic acts peaked in the size range of 15 to $20 \mathrm{~mm}$ carapace width, perhaps indicating that interactions for resources may be most intense in these life history stages in the field. Interestingly, refugia in this size range had the highest occupancy in Shervette et al.'s (2001) study. As expected from the game theory, the frequency of behavioral interactions was higher when individuals were of roughly equal size.
Body size thus plays an obvious role in dominance, as the larger crab in the pair was always more agonistic and retreated less. However, Eurypanopeus depressus was usually dominant over Panopeus simpsoni, even though it is a smaller crab on average.

Also as expected from the game theory, Menippe adina, since it is the dominant species, has a greater RHP if paired with equal-sized individuals of Panopeus simpsoni, for both food and shelter resources. If $P$. simpsoni is larger, RHP shifts for food resources, but not for shelter. This may indicate that shelter resources are considered of higher value, perhaps because they are more limiting in the field (Beck 1995, 1997).

Finally, our data suggest that aggressive interactions may be important to the foraging ecology and distribution of mud crabs. The 2 most agonistic species are also most abundant in the subtidal oyster reef, the least stressful habitat for desiccation and the habitat that provides continual availability of shelter and food. The fact that Menippe adina is at least equally aggressive, even when smaller than its opponent, may explain why this species is able to co-exist and eventually grow through the size range at which it would interact with the other 2 xanthid species. In comparison, the least dominant species, Panopeus simpsoni, tended to occur on the intertidal reef or subtidal mudflat, possibly suboptimal habitats because of the threat of desiccation or lack of refugia (May 1974, Meyer 1994).

Of course, behavioral interactions are only 1 factor determining the distribution of xanthid crabs. On a larger spatial scale, Menippe adina and Panopeus simpsoni are most common at high salinity coastal sites, while Eurypanopeus depressus is found at lower salinities at more estuarine sites (May 1974). E. depressus is more tolerant of salinities lower than 10 PSU in laboratory experiments (Y. Hulathduwa pers. comm., and unpubl. results of our own laboratory). In fact, we selected our sampling sites to be close together to minimize salinity differences. It is also important to note that other studies have found E. depressus to be associated with the upper portions of oyster reefs, perhaps because their smaller size facilitates hiding in small crevices among exposed oysters (Meyer 1994). The fact that E. depressus is also more omnivorous than the other 2 species may also be important in niche-partitioning, along with its more $r$-selected life-history strategy (McDonald 1982).

However, our laboratory results are at least congruent with the hypothesis that the differences in habitat use we observed could have a proximal cause based on behavioral interactions, and we suggest that behavioral hierarchies should be taken into account when considering explanations for co-occurrence and distribution of other crab species as well. 
Acknowledgements. We would like to thank the Louisiana Universities Marine Consortium for use of their laboratory, and Wilton Delaune in particular.

\section{LITERATURE CITED}

Austad SN (1989) Game theory and the evolution of animal contests. Trends Ecol Evol 4:2-3

Beck MW (1995) Size-specific shelter limitation in stone crabs: a test of the demographic bottleneck hypothesis. Ecology 76:968-980

Beck MW (1997) A test of generality of the effects of shelter bottlenecks in four stone crab populations. Ecology 78 : 968-980

Brown KM (1997) Size-specific aspects of the foraging ecology of the southern oyster drill, Stramonita haemastoma. J Exp Mar Biol Ecol 214:249-262

Clark ME, Wolcott TG, Wolcott DL, Hines AH (1999) Foraging and agonistic activity co-occurring in free-ranging blue crabs (Callinectes sapidus): observation of animals by ultrasound telemetry. J Exp Mar Biol Ecol 233:143-160

Conover WJ (1999) Some methods based on ranks. In: Wiley B, Sullivan MO (eds) Practical nonparametric statistics. John Wiley \& Sons, New York, p 288-297

Dingle H (1983) Strategies of agonistic behavior in Crustacea. In: Rebach S, Dunham D (eds) Studies in adaptation, the behavior of higher Crustacea. John Wiley \& Sons, New York, p 85-111

Guillory V, Perry HM, Leard RL (2001) A profile of the western gulf stone crab, Menippe adina. Gulf States Mar Fish Publ 31:1-49

Huber ME, Coles SL (1986) Resource utilization and competition among the five Hawaiian species of Trapezia (Crustacea, Brachyura). Mar Ecol Prog Ser 30:21-31

Huntingford FA, Turner AK (1987) Animal conflict. Chapman \& Hall, London

Huntingford FA, Smith IP, Thorpe KE (1995) Behavioral and physiological studies of aggression in swimming crabs. J Exp Mar Biol Ecol 193:21-39

Iribarne O, Fernandez M, Armstrong D (1994) Does space competition regulate density of juvenile Dungeness crab Cancer magister? J Exp Mar Biol Ecol 183:259-271

Lee SY, Kneib RT (1994) Effects of biogenic structure on prey consumption by the xanthid crabs Eurytium limosum and Panopeus herbstii in a salt marsh. Mar Ecol Prog Ser 104: 39-47

Lindberg WJ, Frazer TK, Stanton GR (1990) Population effects of refuge dispersion for adult stone crabs (Xanthidae, Menippe). Mar Ecol Prog Ser 66:239-249

Mansour RA, Lipcius RN (1991) Density-dependent foraging and mutual interference in blue crabs preying upon infaunal clams. Mar Ecol Prog Ser 72:239-246

May EB (1974) The distribution of mud crabs (Xanthidae) in

Editorial responsibility: Roger Hughes (Contributing Editor), Bangor, UK
Alabama estuaries. Proc Natl Shellfish Assoc 64:33-37

Maynard-Smith J (1982) Evolution and the theory of games. Cambridge University Press, Cambridge

McDonald J (1982) Divergent life history patterns in the cooccurring intertidal crabs Panopeus herbstii and Eurypanopeus depressus (Crustacea: Brachyura: Xanthidae). Mar Ecol Prog Ser 8:173-180

Menendez RJ (1987) Vertical zonation of the xanthid mud crabs Panopeus obesus and Panopeus simpsonii on oyster bars. Bull Mar Sci 10:73-77

Meyer DL (1994) Habitat partitioning between the xanthid crabs Panopeus herbstii and Eurypanopeus depressus on intertidal oyster reefs (Crassostrea virginica) in Southeastern North Carolina. Estuaries 17:674-679

Mittelbach GG (1988) Competition among refuging sunfishes and effects of fish density on littoral zone invertebrates. Ecology 69:614-623

Navarette SA, Castilla JC (1990) Resource partitioning between intertidal predatory crabs: interference and refuge utilization. J Exp Mar Biol Ecol 143:101-129

SAS Institute (1988) SAS user's guide: statistics. SAS Institute, Cary, NC

Shervette V, Perry H, Biesiot P, Larsen K, Warren J (2001) Build it, but will they come? Preliminary findings of refuge limitation bottlenecking in juvenile Menippe adina in the Mississippi sound. In: Creswell RL (ed) Proc 52nd Annual Gulf and Caribbean Fish Inst, Fort Pierce, FL, p 531-540

Sinclair ME (1977) Agonistic behavior of the stone crab, Menippe mercenaria (Say). Anim Behav 25:193-207

Smith IP, Huntingford FA, Atkinson RJA, Taylor AC (1994) Strategic decisions during agonistic behavior in the vervet swimming crab, Necora puber (L.). Anim Behav 47: 885-894

Sneddon LU, Huntingford FA, Taylor AC (1997a) Weapon size versus body size as a predictor of winning in fights between shore crabs, Carcinus maenus (L.). Behav Ecol Sociobiol 41:237-242

Sneddon LU, Huntington FA, Taylor AC (1997b) The influence of resource value on the agonistic behavior of the shore crab, Carcinus maenas (L.). Mar Freshw Behav Physiol 30:225-237

Sokal RR, Rohlf FJ (1995) Biometry. The principles and practice of statistics in biological research, 3rd edn. WH Freeman, New York

Steger R (1987) Effects of refuges and recruitment on gonodactylid stomatopods, a guild of mobile prey. Ecology 68:1520-1533

Stuck KC, Perry HM (1992) Life history characteristics of Menippe adina in coastal Mississippi waters. Fla Mar Res Publ 50:82-98

Turner GF, Huntingford FA (1986) A problem for game theory analysis: assessment and intention in male mouthbrooder contests. Anim Behav 34:961-970

Submitted: May 12, 2004; Accepted: October 13, 2004

Proofs received from author(s): April 1, 2005 